Eur J Clin Chem Clin Biochem

1995; 33:939-945

(c) 1995 Walter de Gruyter \& Co.

Berlin $\cdot$ New York

\title{
Determination of Insulin-Like Growth Factor 1 in Dogs Using a Commercially Available Immunoradiometric Assay ${ }^{1}$ )
}

\author{
By Asger Lundorff Jensen ${ }^{1}$ and René Hoier ${ }^{2}$ \\ 1 Centrallaboratoriet \\ 2 Reproduktion \\ Klinisk Institut, Den Kgl. Veterincer- og Landbohøjskole, Frederiksberg C, Denmark
}

(Received June 13/August 10, 1995)

Summary: The objective of the present study was to characterize a commercially available immunoradiometric assay (IRMA) intended for the determination of human insulin-like growth factor 1 (IGF-1) when used to determine IGF-1 in canine plasma samples. The assay was evaluated by assessment of the precision, accuracy, and detection limit, and by comparing the IGF-1 values observed in healthy dogs and in dogs with acromegaly and hereditary pituitary dwarfism to values reported in the literature. Since extraction of IGF-1 from its binding proteins is essential for reliable test results, the efficiency of the extraction method used in the assay was also examined.

The main conclusions can be summarized as follows: The commercially available IRMA method offers a precise determination of the IGF-1 concentration in canine plasma samples with IGF-1 values directly comparable to those obtained by others. The assay accuracy was confirmed for normal dogs by parallelity between IGF-1 concentrations and plasma dilutions, whereas plasma from acromegalic dogs could not fullful parallelity. The detection limit was below the IGF-1 concentrations observed in dogs with hereditary pituitary dwarfism. In plasma samples with low or normal IGF-1 levels, the assay's extraction efficiency was comparable to that found using other extraction methods. In samples with IGF-1 concentrations above usual physiological levels, the extraction efficiency decreased unexplainably. However, this decrease in extraction efficiency seems to be of only minor importance when the measurements are used in the diagnosis of canine acromegaly.

\section{Introduction}

Canine insulin-like growth factor 1 (IGF-1, somatomedin $\mathrm{C}(1-3))$ is one of the peptides responsible for the effects of somatotropin (growth hormone), and determinations of this component are used to evaluate the somatotropin status in dogs, for instance when diagnosing hereditary pituitary dwarfism and acromegaly $(4,5)$.

Previously, canine IGF-1 was determined using assays not commercially available, thus restricting determination of the peptide to specialized laboratories. We therefore decided to investigate whether a commercially ac-

\footnotetext{
I) Source of support:

Project no. 13-4633-1 of the Danish Agricultural and Veterinary Research Council
}

cessible assay for the determination of human IGF-1 (Diagnostic Systems Laboratories, Inc., Texas, USA; DSL) could be used to measure canine IGF-1 as well. A major analytical problem when measuring IFG-1 is the presence of strong molecular interactive forces between IGF-1 and its binding proteins (e.g. 1, 2,6). The problem is managed by extraction of IGF-1 from the biological material prior to analysis. Among the many approaches that have been used to obtain an effective and reproducible extraction method, acidic column chromatography is generally considered to be the reference method (e.g. 7, 8). However, this method is laborious and expensive, thus being less attractive for routine purposes. A recent comparison between different IGF-1 extraction methods used on rat blood gave as result that the best correlation to acidic column chromatography 
(8) was offered by acid-ethanol cryoprecipitation; the extraction recovery rates ranged from $76 \%$ to $80 \%$. In the IRMA method, extraction of IGF-1 was accomplished by acid-ethanol precipitation and a further objective of the present study was, therefore, to estimate the efficiency of this extraction method to liberate canine IGF-1 from its binding proteins.

\section{Material and Methods}

Collection of plasma samples for characterization of the assay

The canine plasma samples used for characterization of the analysis for IGF-1 were isolated from blood samples from clinically healthy dogs and from hospitalized dogs of different breeds, ages and sexes. Blood samples were also collected from female dogs suffering from acromegaly and from German Shepherd dogs suffering from pituitary dwarfism. The diagnoses of acromegaly and pituitary dwarfism were established by other means than determination of IGF-1 (e. g., classical clinical signs, response to clonidine stimulation test, response to glucose tolerance test, effect of ovariohysterectomy). The blood samples were obtained by puncture of a jugular or cephalic vein and collected into heparinated vials (Vacutainer ${ }^{\circledR}$, Becton-Dickinson; USA). Plasma was isolated by centrifugation of the blood samples $(750 \mathrm{~g}$ for $5 \mathrm{~min}$ ) immediately after collection. Plasma samples were stored at $-55^{\circ} \mathrm{C}$ until analysis.

Collection of plasma samples for estimation of the inter-and intra-individual coefficient of variation

Four unrelated male Beagle dogs (aged 2-3 years) and four unrelated female Labrador dogs (aged $1-2$ years) were included in the study. The dogs were all clinically healthy prior to and during the study, and they had not received any medication for 3 weeks prior to and throughout the study. The dogs were fasted 15 hours prior to each collection of blood samples. Water was offered ad libitum during the study.

Blood samples were collected between 8.30 and 9.30 a.m. at 7day intervals for 3 weeks. On each occasion, blood was collected while care was taken not to excite the dogs in order to reduce any effect from stress, handling and transport etc. Plasma was obtained by centrifugation and stored as described above for no longer than 45 days. All samples were subjected to duplicate analysis in one analytical run using the same set of reagents, calibrators and controls.

\section{Analysis for IGF-1 in canine plasma}

The analysis for IGF-1 in canine plasma was performed with a commercial IRMA designed for determination of human IGF-1 (DSL; preliminary protocol of 20/10/93 and amended protocol of 19/09/94). The kit is a sandwich-type solid phase immunoradiometric assay with anti-human IGF-1 antibody immobilised to the wall of test tubes in which standard human IGF-1 amounts (0 to approximately $78 \mathrm{nmol} / \mathrm{l}$ ) and sample extracts were incubated together with ${ }^{125}$ I-labelled anti-human IGF-1 antibody. Following decantation and washing, the bound tracer was quantified by counting in a $\gamma$-counter for $60 \mathrm{~s}$. Samples were prepared for analysis by extraction with four volumes of the kit's extraction solution, which consisted of $2.0 \mathrm{~mol} / 1 \mathrm{HCl}$, volume fraction 0.125 in absolute ethanol. This method was reported in the protocol to recover $90-100 \%$ of added IGF-1 from human blood. The dilution factor between blood concentration and concentration of IGF-1 in the assay was 15.

Previous investigations have reported that the plasma IGF-1 concentration in dogs ranged from about $1 \mathrm{nmol} / \mathrm{l}$ for German Shep- herd dogs with hereditary pituitary dwarfism (9) to about $90 \mathrm{nmol} / 1$ in acromegalic dogs (10), all results achieved using human IGF-1 for calibration. Thus, the kit's standards $(1.17$ to $52 \mathrm{nmol} / \mathrm{l}$ in the preliminary and 0.65 to $78.0 \mathrm{nmol} / \mathrm{l}$ in the amended protocol, calibrated against the WHO reference 87/518) covered well the IGF1 levels usually found in dogs. IGF-1 concentrations were reported in SI-units, i.e. nmol/l; to convert from "traditional" units (ng/ $\mathrm{ml}$ ) to SI-units, multiply the number in "traditional" units by 0.13 $\left(M_{\mathrm{r}}=7600\right)$.

\section{Analytical specificy}

The DSL IGF-1 IRMA kit was reported to represent the following cross-reactivities against human peptide hormones: IGF-1 $100 \%$; insulin-like growth factor 2 (IGF-2) 3\%; insulin, pro-insulin and somatotropin not detectable. Data on cross-reactivity to canine peptide hormones were not available. The cross-creactivity to canine insulin was investigated by analysing various concentrations of porcine insulin, since canine and porcine insulin have been reported to be structurally identical (11).

\section{Precision of the IGF-1 analysis}

The intra-assay variation was monitored as the coefficient of variation (CV\%) for the difference between single observations of duplicates according to pooled-variance estimates at three IGF-1 concentrations ( $\mathrm{n}=14,18,7$, respectively). The inter-assay variation was recorded as the CV\% for two control specimens analysed in different assays ( $n=5,4$, respectively).

\section{Accuracy of the IGF-1 analysis}

To assess the accuracy of the assay, various dilutions of plasma samples from a healthy dog and from two acromegalic dogs, respectively, were prepared by mixing with the kit's 0-standard, since parallelity between dilution of samples and measured IGF-1 concentrations is likely to indicate that blood components do not confound the assay system. The plasma dilutions were extracted once according to the protocol suggested by the manufacturer and subjected to analysis ( $\mathrm{n}=16$ for each plasma specimen).

\section{Limit of detection}

The limit of detection, defined as the smallest single observation which could be distinguished from zero, was calculated as the least detectable concentration at a probability level of 0.05 . A pooledvariance estimate of low-IGF-1 samples $(n=9)$ was used to calculate the standard deviation (SD) at concentration close to zero concentrations, and the limit of detection was calculated as $2.3 \cdot \mathrm{SD}$.

\section{Investigation of extraction efficiency}

Plasma samples used for the investigation of assay accuracy were subjected to repeated acid-ethanol precipitation (four times totally) in order to estimate the total IGF-1 content of the material. The 3rd and the 4th extraction did not show measurable amounts of IGF-1 and were therefore excluded from the subsequent calculations: in order to quantify the extraction efficiency, the ratio of the IGF-1 concentration obtained following the first extraction was calculated relative to the estimated total IGF-1 concentration.

\section{Statistical methods}

Descriptive statistics, correlation between sample dilution and measured IGF-1 using untransformed data and logarithmically transformed data, performance of lack-of-fit test (LOF test) were calculated as previously described $(12,13)$.

Fraser \& Harris (14) have proposed that the maximum value of $\mathrm{CV} \%_{\text {Anal. }}$ is half the intra-individual coefficient of variance (i. e., 
$\left.1 / 2 \cdot C V \%_{\text {Intra }}\right)$ when the analysis is used to aid in diagnosis or to monitor therapy by single or serial testing in one individual. $\mathrm{CV} \%_{\text {Intra }}$ was calculated as previously described $(14,15)$ using the entire set of test results from the 4 Beagles and 4 Labradors over the 3 weeks period.

\section{Results}

\section{Specificity}

The cross-reactivity to canine insulin was insignificant at blood concentrations up to $12.5 \mu \mathrm{mol} / \mathrm{l}$. In terms of linear regression, $(x, y)=$ (added insulin, measured IGF-1): $y=0.04163-0.008395 \times$ added insulin, $\mathrm{p}\left(\beta_{1}=0\right)=0.07, \mathrm{n}=18, \mathrm{r}=-0.4375, \mathrm{n}=18$.

\section{Precision}

The intra- and inter-assay CV\% at different IGF-1 concentrations are presented in table 1. Intra-assay $\mathrm{CV} \%$ ranged between $6 \%$ and $10 \%$, and the inter-assay CV\% was around $10 \%$.

\section{Accuracy}

IGF-1 concentrations were measured in various dilutions of plasma samples from a healthy and two acromegalic dogs, respectively ( $n=4$ for each of 4 dilutions per dog). Also, extracts of acromegalic plasma samples were diluted and subsequently assayed. The results, outlined in figure 1 and table 2, show that the dilution curve derived from plasma of a healthy dog appeared as a straight line since a test for model fitting was non-significant $(\mathrm{p}(\mathrm{LOF})=0.53)$. Following logarithmic transformation it could be shown that there existed proportionality between the measured amount of IGF-1 and the degree of dilution as evidenced by the straight-line relationship $(p(L O F)=0.40)$ together with a slope not

Tab. 1 Intra- and inter-assay coefficient of variation of the determination of canine IGF-1

\begin{tabular}{lrrll}
\hline & $\mathrm{n}^{\mathrm{a}}$ & $\begin{array}{l}\text { Mean } \\
(\mathrm{nmol} / \mathrm{l})\end{array}$ & $\begin{array}{l}\mathrm{SD}^{\mathrm{b}} \\
(\mathrm{nmol} / \mathrm{l})\end{array}$ & $\begin{array}{l}\mathrm{CV}^{\mathrm{c}} \\
(\%)\end{array}$ \\
\hline $\begin{array}{l}\text { Intra-assay variation } \\
\quad \text { low IGF-1 }\end{array}$ & 14 & 6.2 & 0.6 & 9.7 \\
$\quad \begin{array}{l}\text { medium IGF-1 } \\
\text { high IGF-1 }\end{array}$ & 18 & 18.6 & 1.3 & 7.0 \\
& 7 & 42.6 & 2.6 & 6.1 \\
$\begin{array}{l}\text { Inter-assay variation } \\
\quad \text { low IGF-1 }\end{array}$ & & & & \\
$\quad$ medium IGF-1 & 5 & 3.7 & 0.4 & 10.8 \\
\hline
\end{tabular}

number of observations;

b standard deviation;

c CV coefficient of variation;

d calculated from a pooled-variance estimate of differences between duplicate determinations at three IGF-1 concentrations;

c calculated from means of duplicates at two IGF-1 concentrations. different from unity $(p=0.72)$. In contrast, the dilution curve derived from plasma from two acromegalic dogs did not fit a straight-line model properly ( $p(L O F)$ $<0.0001$ ), neither when untransformed nor logarithmically transformed data were correlated. The curve for dilution of extracts from acromegalic dogs did not appear straight-lined, either $(p(L O F)<0.0001)$.

Estimation of the inter-and intra-individual coefficient of variation

From the results of the 4 Beagles and 4 Labradors, the total variance $\left(\mathrm{S}_{\text {Total }}^{2}\right)$ was estimated as 78.2 , the interindividual variance $\left(\mathrm{S}_{\text {Inter }}^{2}\right)$ as 63.9 , the intra-individual variance $\left(S_{\text {Intra }}^{2}\right)$ as 12.7 , and the analytical variance $\left(\mathrm{S}_{\text {Anal. }}^{2}\right)$ as 1.6. The overall mean IGF-1 concentration was calculated as $17.0 \pm 2.9 \mathrm{nmol} / \mathrm{l}$. Based on these components of variance and the overall mean value, $\mathrm{CV} \%_{\text {Intra }}$ was calculated as $21.0 \%$, and $\mathrm{CV} \%_{\text {Anal. }}$ was calculated as $7.4 \%$. Hence, the maximum value for $\mathrm{CV} \%_{\text {Anal. }}$ was $10.5 \%$ for individual testing.

\section{Limit of detection}

The limit of detection was calculated as $0.2 \mathrm{nmol} / 1$ (SD $0.1 \mathrm{nmol} / \mathrm{l}$ ), thus depicting a least detectable concentration well below the expected IGF-1 concentrations in

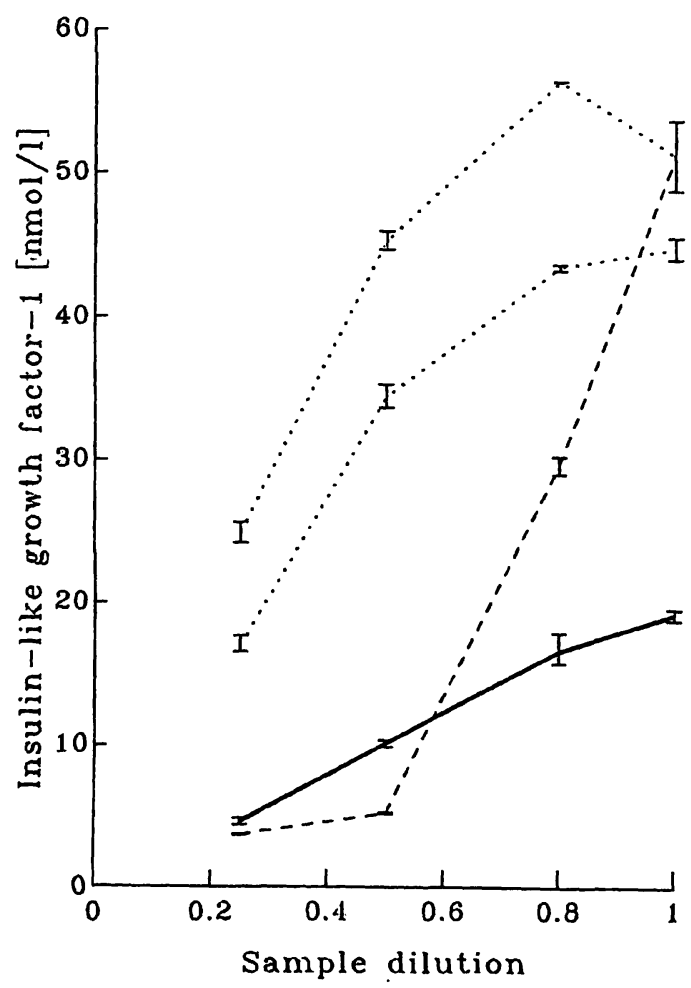

Fig. 1 The IGF-1 concentration following dilution of plasma samples from a healthy dog (solid line), two acromegalic dogs (dotted lines), and dilutions of extract of plasma from an acromegalic dog (dashed line). The samples were diluted with the 0-standard supplied with the commercially availably IRMA kit. SEM (error bar) is the standard error on the mean. 
plasma from healthy dogs and below the IGF-1 concentrations observed in the German Shepherd dogs with hereditary pituitary dwarfism, albeit close.

IGF-1 levels in healthy dogs and in dogs suffering from acromegaly and dwarfism

The plasma IGF-1 concentrations as determined by the employed method in healthy dogs, in dogs with acromegaly, and in dogs with hereditary pituitary dwarfism are shown in table 3 .

\section{Extraction efficiency}

The ratios of the IGF-1 concentration following the first extraction to the estimated total IGF-1 concentration are summarized in figure 2, and it can be seen that plasma specimens with different IGF-1 concentrations were extracted in different ways. Using plasma samples from a healthy dog, the ratio averaged 0.84 (corresponding to an extraction efficiency of $84 \%$ ), and dilution of the samples did not affect the extraction recovery significantly $(\mathrm{p}($ slope $=0)=0.10$ in linear regression). In the samples from acromegalic dogs, however, the ratio ranged from 0.73 to 0.85 , the lowest ratio being observed in extracts of undiluted plasma.

\section{Discussion}

Although the amino acid sequence of canine IGF-1 is not known at present, the antibody against human IGF-1 used in this study cross-reacted with canine IGF-1, since the assay clearly detected the decreased IGF-1 levels expected to be found in dogs with hereditary pituitary dwarfism and the expected augmented IGF-1 levels in acromegalic dogs. The close interspecies similarity with respect to the structure of IGF-1 found in this study is in agreement with the previously reported high degree of conservation of IGF-1 structure (2) and is further sup- ported by the fact that previously published methods for measurement of canine IGF-1 were all evaluated by use of antibodies directed against human IGF-1, and using human IGF-1 for calibration and tracer preparation (9, $10,16)$.

The specificty of the analysis could not be fully investigated due to the scarce supply of canine IGF varieties. However, we analysed the cross-reactivity to canine insulin by measuring the response from porcine insulin, since identity between beteen canine and porcine insulin has previously been reported (11). The analysis appeared to be specific since no response could be detected from insulin concentrations up to $12.5 \mu \mathrm{mol} / \mathrm{l}$ in the blood. The findings presented in table 1 show that the concentration of IGF-1 in canine plasma samples can be precisely measured with intra- and inter-assay coefficients of variation within acceptable ranges at IGF-1 concentrations expected be found in dogs. The intra- and interassay CV\% of the present study were acceptable when compared to methods involving both extraction and analytical variation; thus, Eigenmann et al. (10) reported intra- and inter-assay variation for the determination of IGF-1 in dogs to be $16.7 \%$ and $21.7 \%$, respectively. The limit of detection of the assay $(0.2 \mathrm{nmol} / \mathrm{l})$ was well below the IGF-1 concentrations commonly observed in healthy dogs, and also lower than the IGF-1 concentrations in dogs with hereditary pituitary dwarfism.

The accuracy of the analysis (fig. 1) was outlined as the presence of parallelism between dilutions of plasma samples from a healthy dog and the measured concentrations of IGF-1. This finding is in agreement with the amended protocol of the kit which claims proportionality between degree of dilution and results of analysis if diluted samples are extracted and analyzed or if extracted sample is diluted and analyzed, when normal human plasma samples are investigated. Plasma samples from acromegalic dogs, however, did not depict parallelism between degree of dilution and measured concen-

Tab. 2 Accuracy of the IGF-1 assay: Regression analyses of untransformed (linear) and logarithmically transformed data of the IGF-1 content (nmol/l) in dilutions of plasma samples

\begin{tabular}{|c|c|c|c|c|c|c|}
\hline & $\mathrm{n}^{\mathrm{a}}$ & Intercept $t^{b}$ & Slope $^{c}$ & $\mathbf{r}^{d}$ & $\mathrm{p}(\mathrm{LOF})^{\mathrm{e}}$ & $p(\text { slope })^{f}$ \\
\hline \multicolumn{7}{|c|}{ Linear regression } \\
\hline $\begin{array}{l}\text { Healthyg } \\
\text { Acromegalic }^{h}\end{array}$ & $\begin{array}{l}16 \\
32\end{array}$ & $\begin{array}{l}0.207 \\
11.56\end{array}$ & $\begin{array}{l}18.98 \\
36.32\end{array}$ & $\begin{array}{l}0.987 \\
0.939\end{array}$ & $\begin{array}{l}0.53 \\
<0.0001\end{array}$ & - \\
\hline \multicolumn{7}{|c|}{ Logarithmic regression } \\
\hline $\begin{array}{l}\text { Healthy } \\
\text { Acromegalic }\end{array}$ & $\begin{array}{l}16 \\
32 \\
\end{array}$ & $\begin{array}{l}2.965 \\
3.892 \\
\end{array}$ & $\begin{array}{l}1.013 \\
0.714\end{array}$ & $\begin{array}{l}0.991 \\
0.965\end{array}$ & $\begin{array}{c}0.40 \\
<0.0001\end{array}$ & $\begin{array}{c}0.72 \\
<0: 0001 \\
\end{array}$ \\
\hline \multicolumn{3}{|c|}{$\begin{array}{l}\text { a number of observations; } \\
\text { b intercept of the regression line; } \\
\text { the slope of regression line; } \\
\text { d coefficient of correlation; }\end{array}$} & \multicolumn{4}{|c|}{$\begin{array}{l}\text { c the probability of fitting to the straight line model; } \\
\text { f the probability of the slope being equal to unity; } \\
\text { g plasma sample from a healthy dog; } \\
\text { i plasma samples from two acromegalic dogs. }\end{array}$} \\
\hline
\end{tabular}


tration of IGF-1; the kit's protocol does not describe dilution curves from samples from acromegalic individuals. It could be argued that the dilution of plasma with the kit's 0 standard merely dilutes the strongly attached IGF-1 : IGF-1 binding protein (IGFBP-3) complexes, and therefore a skewed dilution curve might be expected due to dissociation of the complexes. Meanwhile, this is contradicted by the fact that the dilution curve from the healthy dog expressed linearity between degree of dilution and the measured IGF-1 concentration. As indicated in figure 2 , the reason for this discrepancy might be a

Tab. 3 Plasma IGF-1 concentrations in healthy dogs, in dogs suffering from acromegaly, and in dogs suffering from hereditary pituitary dwarfism

\begin{tabular}{lrlll}
\hline & $\mathrm{n}^{\mathrm{a}}$ & $\begin{array}{l}\text { Range }^{\mathrm{b}} \\
(\mathrm{nmol} / \mathrm{l})\end{array}$ & $\begin{array}{l}\text { Mean } \\
(\mathrm{nmol} / \mathrm{l})\end{array}$ & $\begin{array}{l}\mathrm{SEM}^{\mathrm{c}} \\
(\mathrm{nmol} / \mathrm{l})\end{array}$ \\
\hline Healthy dogs & 16 & $3.1-32.2$ & 15.2 & 2.1 \\
Acromgalic dogs & 7 & $5.8-79.3$ & 46.8 & 8.1 \\
Dwarfs & 4 & $0.4-2.0$ & 1.0 & 0.4 \\
\hline
\end{tabular}

a number of observations;

b highest and lowest IGF-1 concentration measured;

c standard error on the mean.

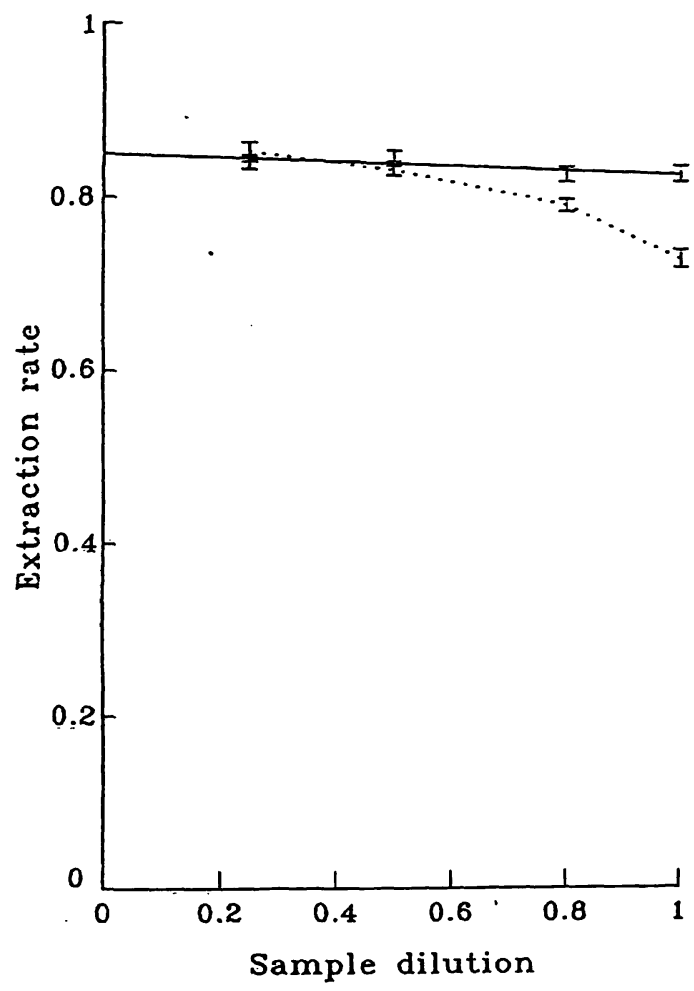

Fig. 2 Efficiency of the extraction method used in the IRMA method (acid-ethanol precipitation) to liberate IGF-1 from its binding proteins in plasma samples from a healthy dog (solid line) and an acromegalic dog (dotted line) in various dilutions. The extraction efficiency is depicted as the rate of the IGF-1 concentration following the first extraction to the estimated total IGF-I concentration in the samples. The total IGF-1 concentration in the samples was estimated as the total amount of IGF-1 measured during 4 extractions. The 0 -standard supplied with the assay was used as diluent. SEM (error bar) is the standard error on the mean. less effective extraction of very high concentrations of IGF-1 (see below). It could also be argued that both extraction rate and accuracy of the assay could be investigated more precisely by extraction and analysis of samples to which known amounts of IGF-1 were added. However, purified canine IGF-1 is scarce. In addition, samples constructed by addition of IGF-1 but not IGF-1 binding proteins might release IGF-1 more easily during extraction due to shortage of binding proteins, thereby confounding the extraction efficiency.

The estimates of the inter- and intra-individual plus analytical components of variance further supported the clinical usefulness of the assay, the analytical variance ( $\mathrm{CV}=7.4 \%$ ) being lower than the maximum tolerable values $(10.5 \%)$ estimated from the various components of variance.

The extraction efficiency $(73 \%-85 \%)$ of the acid-ethanol precipitation used in this study is comparable with those previously reported, which ranged from $79 \%$ (8) to $93 \%(16)$. In the present study, the extraction efficiency was about $85 \%$ for plasma from healthy dogs, while the efficiency was lower, approximately $73 \%$, for undiluted plasma samples from acromegalic dogs. Several explanations may account for this discrepancy:

Firstly, our estimates of the total IGF-1 concentration are based on the assumption that it is possible to release all IGF-1 from its binding proteins by repeated extractions.

Secondly, it may be that the concentrations of the various IGF-1 binding proteins in acromegalic dogs are of importance. For instance, IGFBP-3 (e.g. 1) is probably primarily regulated by somatotropin $(6,17)$, and it is likely that in canine acromegaly, the progestin-induced somatotropin excess originating from the mammary gland (18), besides inducing an increase in the plasma IGF-1 level (19) also induces an increase in IGFBP-3. If this hypothesis is true, an excess of IGFBP-3 in the blood from acromegalic dogs might inhibit the release of IGF-1 during extraction.

Thirdly, a carry-over of IGFBP-3 during extraction would be expected to disturb the binding of IGF-1 to the antibody during the assay, and in fact the non-linear curve found after dilution of extracted acromegalic material indicates that the analysis for IGF-1 might be affected significantly by material extracted from the blood. However, this hypothesis is contradicted by the straight-line recoveries seen from analysis of plasma from a normal dog, unless the profile and effect of the IGF-1 binding proteins are altered during acromegaly. Differences might exist between the tertiary structures of human and canine IGF-1, and therefore, the affinity of the antibody against canine IGF-1 might be lower 
than the affinity for human IGF-1, although this explanation is not in agreement with the linear relationship between degree of dilution of measured IGF-1 in blood from a normal dog. However, if the latter hypothesis is true, the decrease in extraction rate seen in undiluted or slightly diluted plasma from an acromegalic dog, besides being an indication of differences between human and canine IGF-1, is an underestimation of high IGF-1 concentrations rather than a decrease in extraction rate. The problem concerning dilution of material from acromegalic individuals awaites further investigation.

Despite the reduced extraction efficiency at high IGF-1 levels, the assay still generates IGF-1 values that are directly comparable to those reported earlier. For German Shepherd dogs with hereditary pituitary dwarfism, Eigenmann et al. (9) reported a plasma IGF-1 level of $1.5 \pm 0.3 \mathrm{nmol} / \mathrm{l}$ (mean $\pm \mathrm{SEM}$ ), while in the present study the level was $1.0 \pm 0.4 \mathrm{nmol} / \mathrm{l}$. In healthy dogs, the plasma IGF-1 level depends on various factors such as breed, age, and body size $(10,20)$ and therefore, specific reference ranges are difficult to obtain. However, the healthy adult Beagles and Labradors used in the present study had a mean plasma IGF-1 concentration of $17.0 \pm 2.9 \mathrm{nmol} / \mathrm{l}$, a value that is comparable to the IGF1 levels found by Eigenmann et al. (10) in healthy, adult Beagles $(11.3 \pm 4.3 \mathrm{nmol} / \mathrm{l})$ and Kesshonds $(15.2 \pm 4.4$ $\mathrm{nmol} / \mathrm{l})$. The mean plasma IGF-1 concentration of the 7 acromegalic dogs in the present study (46.8 \pm 8.1 $\mathrm{nmol} / \mathrm{l}$ ) is lower than reported by Eigenmann et al. (19) for 29 acromegalic dogs of different breeds $(91.0 \pm 11.7$ nmol/l). Part of this discrepancy might be accounted for by the decreased extraction rate found in this study. Thus, if the IGF-1 concentrations in acromegalic dogs were measured following an initial 2-fold dilution of the samples due to expectations of values exceeding the calibrator range, our mean concentration for acromegalic dogs would have been above $60 \mathrm{nmol} / \mathrm{l}$, a value which is much closer to the level reported by Eigenmann et al. (10).

In summary, the commercial IRMA method used in the present study can be used to measure the plasma IGF-1 concentration in dogs, and it generates IGF-1 concentrations that are directly comparable to those obtained by other methods. The measurements are precise, at least for normal dogs and dogs suffering from pituitary dwarfism. In addition, the method fulfills current demands to the analytical variance when compared to the biological variation. Except for plasma IGF-1 concentrations above the physiological level, the assay's efficiency in extracting IGF-1 from its binding proteins is comparable to that found when using other methods. In plasma samples with higher IFG-1 concentrations, the assay's extraction efficiency decreases unexplainably. This deviance in extraction efficiency appears, however, to be of minor importance for the diagnosis of canine growth hormone abnormalities.

\section{Acknowledgements}

The skillful technical assistance of Mrs. V. S. Østvedt and Mrs. E. Thomsen is gratefully acknowledged.

\section{References}

1. Clemmons DR. IGF binding proteins and their functions. Mol Rep Devel 1993; 35:368-75.

2. Rudd BT. Growth, growth hormone and the somatomedins: a historical perspective and current concepts. Ann Clin Biochem 1991; 28:542-55.

3. Sara VR, Hall K. Insulin-like growth factors and their binding proteins 1990; Physiol Rev 70:591-614.

4. Feldman EC, Nelson RW. Growth hormone. In: Pedersen D, editor. Canine and feline endocrinology and reproduction. Philadelphia: W. B. Saunders Company, 1987: 29-54.

5. Jensen AL, Thomsen MK, Aaes H, Andreasen M, Søndergaard J. Polymorphonuclear neutrophil granulocyte chemotactic hyperresponsiveness in a case of canine acromegaly. Vet Immun Immunopathol 1993; 37:329-36.

6. Baxter RC. Characterization of the acid-labile subunit of the growth hormone-dependent insulin like growth factor binding protein complex. J Clin Endocrinol Metab 1988; 67:265-72.

7. Daughaday WH, Rotwein P. Insulin-like growth factors I and II. Peptide, messenger ribonucleic acid and gene structure, serum and tissue concentrations. Endocrine Rev 1989; 10:6891.

8. Rivero F, Goya L, Pascual-Leone AM. Comparison of extraction methods for insulin-like growth factor-binding proteins prior to measurement of insulin-like growth factor- 1 in under-

nourished neonatal and adult rats. J Endocrinol 1994; 140:257-63.

9. Eigenmann JE, Zanesco S, Arnold U, Froesch ER. Growth hormone and insulin-like growth factor I in German Shepherd dwarf dogs. Acta Endocrinol 1984; 105:289-93.

10. Eigenmann JE, Patterson DF, Zapf J, Froesch ER. Insulin-like growth factor $I$ in the dog: a study in different dog breeds and in dogs with growth hormone elevation. Acta Endocrinol 1984; 105:294-301.

11. Kaneko JJ. Carbohydrate metabolism and its diseases. In: Kaneko JJ, editor. Clinical biochemistry of domestic animals. 4th ed. San Diego: Academic Press Inc., 1989: 44-85.

12. Jensen AL, Høier R, Poulsen JSD. Adaptation of a commercially available enzyme linked immunosorbent assay (ELISA) for the determination of thyroxine in canine plasma samples. J Vet Med Series A 1992; 39:741-6.

13. Box GEP, Hunter WG, Hunter JS. Statistics for experimenters. New York, USA: John Wiley \& Sons, Inc., 1978:1-653.

14. Fraser CG, Harris EK. Generation and application of data on biological variation in clinical chemistry. CRC Crit Rev Clin Lab Sci 1989; 29:409-30.

15. Jensen AL, Høier R, Pedersen HD. Evaluation of an enzyme linked immunosorbent assay for the determination of free thyroxine in canine plasma samples assisted by data on biological variation. J Vet Med Series A 1993; 40:539-45. 
16. Nap RC, Mol JA, Hazewinkel HAW. Age-related plasma concentrations of growth hormone $(\mathrm{GH})$ and insulin-like growth factor 1 (IGF-1) in Great Dane pups fed different dietary levels of protein. Dom Anim Endocrinol 1993; 10:327-47.

17. Laron Z, Klinger B, Blum WF, Silbergeld A, Ranke MB. IgF binding protein 3 in patients with Laron type dwarfism: effect of exogenous rIGF-1. Clin Endocrinol 1992; 36:301-4.

18. Selman PJ, Mol JA, Rutteman GR, Van Garderen E, Rijnberk A. Progestin-induced growth hormone excess in the dog originates in the mammary gland. Endocrinology 1994; 134:28792.

19. Simmen FA. Expression of the insulin-like growth factor-I gene and its products: complex regulation by tissue specific and hormonal factors. Dom Anim Endocrinol 1991; 8:165-78.
20. Eigenmann JE, Patterson DF, Froesch ER. Body size parallels insulin-like growth factor 1 levels but not growth hormone secretory capacity. Acta Endocrinol 1984; 106:448-53.

\author{
Asger Lundorff Jensen \\ Centrallaboratoriet \\ Klinisk Institut \\ Den Kgl. Veterinær- og Landbohøjskole \\ Bülowsvej 13 \\ DK-1870 Frederiksberg C \\ Denmark
}


, 